American Journal of Agricultural and Biological Sciences 6 (1): 180-184, 2011

ISSN 1557-4989

(C) 2010 Science Publications

\title{
Influence of Seeding Rate on Weed Density in Soybean Planting System for Southeastern Coastal Plains
}

\author{
${ }^{1}$ Pawel Wiatrak and ${ }^{2}$ Guihua Chen \\ ${ }^{1}$ Department of Entomology, Soils and Plant Sciences, Clemson University, \\ Edisto Research and Education Center, Blackville, SC 29817 \\ ${ }^{2}$ Department of Land, Air and Water Resources, University of California, Davis, \\ 3140 Plant and Environmental Science Building, One Shields Avenue, Davis, 95616, CA
}

\begin{abstract}
Problem statement: Increasing seeding rates may help decrease weed pressure in soybean [Glycine max (L.) Merr.] wide row spacing. Approach: The objective of this study was to evaluate the influence of five glyphosate-resistant soybean Maturity Groups (MG) (IV, V, VI, VII and VIII) and six seeding rates $\left(68,000,136,000,204,000,272,000,340,000\right.$ and 408,000 seeds ha $\left.{ }^{-1}\right)$ on weed density under dryland conditions on the Southeastern coastal plain in 2007-2009. Results: Weed decrease with increasing seeding rate varied over years. Weed density was generally lower at higher seeding rates for most MG soybeans at 30 and 60 DAP, except MG IV and VIII at 30 DAP in 2007 and MG VI at 30 DAP in 2008. At 60 DAP, soybean Leaf Area Index (LAI) and normalized difference vegetation index (NDVI) were greater with lower weed density. Conclusion: Additionally, negative correlations were observed between weed density and plant LAI/NDVI for all MG in 2008 and MG IV through VI in 2009. These results suggest that increased seeding rates may help decrease weed pressure and improve soybean growth at early growth stages. However the response of weed pressure to seeding rate may vary over years and depend on MG soybean.
\end{abstract}

Key words: Soybean planting, maturity group, weed pressure, weed density, grain yield, Normalized Difference Vegetation Index (NDVI), Leaf Area Index (LAI), Days After Planting (DAP), coastal plain, Analysis Of Variance (ANOVA)

\section{INTRODUCTION}

The integrated weed management system must encompass, among other areas, the enhancement of crop competitiveness and modeling of crop-weed interference (Swanton and Weise, 1991). Buhler (1999) stated that crop yields are less sensitive to weed control practices when initial weed densities are low. However, weather affects weed populations and crop yield responses to the weed control treatments over years (Buhler, 1999). Measurements of photosynthetically active radiation indicated increased light penetration to the soil surface with increasing row spacing and therefore greater weed pressure (Yelverton and Coble, 1991). Arce et al. (2009) reported less weed biomass at higher seeding rate. Lowering seeding rates below the optimum level reduces soybean competitiveness with weeds, thereby, reducing seed yield (Rich and Renner, 2007). Soybean leaf area and total biomass are reduced by higher weed density, because weeds compete with crops for moisture, nutrients and light (Legere and
Schreiber, 1989). The objective of this study was to evaluate the effect of soybean $\mathrm{MG}$ and seeding rate on weed pressure and soybean growth.

\section{MATERIALS AND METHODS}

This study was conducted under dryland (nonirrigated) conditions on a Dothan loamy sand soil (fineloamy, siliceous, thermic Plinthic Paleudult) at Clemson University, Edisto Research and Education Center (REC) located near Blackville, SC (33⒉' N, $81^{\circ} 19^{\prime}$ W) on the Southeastern Coastal Plain. Daily precipitation was recorded using an automated weather station located at Edisto REC. A summary of monthly precipitation and the deviation from the 30-yr average during the soybean growing season in 2007-2009 are presented in Table 1. For each Maturity Group (MG) soybean, the study design was a randomized complete block with four replications. The treatments included five Maturity Group (MG) soybeans (IV, V, VI, VII and VIII) and six seeding rates $(68,000,136,000$, 204,000, 272,000, 340,000 and 408,000 seeds ha $\left.{ }^{-1}\right)$.

Corresponding Author: Pawel Wiatrak, Department of Entomology, Soils and Plant Sciences, Clemson University, Edisto Research and Education Center, Blackville, SC 29817 
Am. J. Agri. \& Biol. Sci., 6 (1): 180-184, 2011

Table 1: Precipitation (cm) during soybean growing season at Edisto REC, near Blackville, SC from 2007-2009. Deviations from the 30-yr average reported in parentheses

Month

\begin{tabular}{cccccccccc} 
Year & April & May & June & July & August & September & October & November & Total \\
\hline 2007 & $9.9(1.9)$ & $1.4(-7.4)$ & $15.1(2.2)$ & $11.3(-1.7)$ & $7.0(-5.3)$ & $2.3(-6.9)$ & $3.4(-4.6)$ & $0.9(-5.9)$ & $51.4(-27.5)$ \\
2008 & $6.3(-1.7)$ & $7.6(-1.1)$ & $4.4(-8.5)$ & $14.6(1.6)$ & $16.1(3.9)$ & $5.2(-4.0)$ & $12.4(4.3)$ & $12.5(5.6)$ & $78.9(0.0)$ \\
2009 & $13.7(5.8)$ & $28.4(19.7)$ & $5.4(-7.5)$ & $14.7(1.8)$ & $2.4(-9.9)$ & $8.1(-1.1)$ & $7.6(-0.4)$ & $11.5(4.6)$ & $91.8(12.9)$ \\
\hline
\end{tabular}

Table 2: Seeding rate goals and plant stands 2 wks after planting for maturity group (MG) IV-VIII soybeans from 2007-2009

\begin{tabular}{|c|c|c|c|c|c|c|c|c|c|c|c|c|c|c|c|c|}
\hline \multirow[b]{3}{*}{ Seeding rate } & \multirow[b]{3}{*}{ Goal } & \multicolumn{15}{|l|}{ MG } \\
\hline & & \multicolumn{3}{|l|}{ IV } & \multicolumn{3}{|l|}{$\mathrm{V}$} & \multicolumn{3}{|l|}{ VI } & \multicolumn{3}{|l|}{ VII } & \multicolumn{3}{|l|}{ VIII } \\
\hline & & 2007 & 2008 & 2009 & 2007 & 2008 & 2009 & 2007 & 2008 & 2009 & 2007 & 2008 & 2009 & 2007 & 2008 & 2009 \\
\hline Seeds ha $^{-1}$ & & & & & & & & -Seeds & $\mathrm{m}^{-1}$ rov & & & & & & & 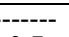 \\
\hline 68000 & 6.6 & $-\dagger$ & 5.0 & 5.3 & - & 4.6 & 5.5 & - & 4.7 & 5.0 & - & 2.8 & 4.4 & - & 2.5 & 3.7 \\
\hline 136000 & 13.2 & 12.1 & 8.5 & 10.2 & 7.4 & 6.8 & 8.9 & 7.3 & 10.6 & 10.1 & 6.9 & 6.1 & 8.4 & 9.1 & 5.4 & 8.2 \\
\hline 204000 & 19.8 & 16.7 & 12.1 & 14.9 & 13.0 & 9.8 & 14.7 & 12.2 & 14.1 & 13.2 & 10.0 & 10.0 & 11.7 & 14.9 & 7.4 & 10.5 \\
\hline 272000 & 26.4 & 22.9 & 17.8 & 20.2 & 16.5 & 12.9 & 17.8 & 19.1 & 17.7 & 19.8 & 12.4 & 14.6 & 13.5 & 17.9 & 10.3 & 14.6 \\
\hline 340000 & 33.0 & 27.1 & 21.2 & 25.8 & 23.0 & 17.3 & 23.5 & 24.4 & 24.0 & 22.8 & 14.9 & 17.9 & 16.8 & 20.0 & 15.0 & 19.0 \\
\hline 408000 & 39.6 & 32.6 & 23.5 & 30.8 & 26.5 & 22.0 & 29.0 & 27.0 & 26.7 & 28.8 & 17.2 & 20.2 & 19.6 & 24.2 & 20.3 & 23.5 \\
\hline
\end{tabular}

$\dagger$ The rate of 68000 seeds ha $^{-1}$ was not applied in 2007

The rate of 68,000 seeds ha $^{-1}$ was not included in 2007. Soybean cultivars were selected based on the South Carolina recommendations and seed availability in each year. Cultivars selected in this study were DP 4331RR, AG 4801 and AG 4705 for MG IV; DP 5915RR, DP 5631 and Pioneer 95 Y70 for MG V; AG 6301, AG 6451 and AG 6301 for MG VI; Pioneer 97M50, V74N4RR and Pioneer 97M50 for MG VII; AGS 825, Prichard RR and Prichard RR for MG VIII in 2007, 2008 and 2009, respectively.

The seedbed was prepared using a 4-row Univerferth Ripper-stripper implement (Unverferth Mtg. Co., Inc., Falida, OH). Planting dates for fullseason (MG IV, V and VI) and double cropping (MG VII and VIII) production were chosen based on the current recommendations in South Carolina. Soybeans were seeded using a 4-row Almaco cone planter (Almaco, Nevada, IA) on 12, 22 and 21 April for MG IV, 9, 8 and 7 May for MG V and VI and 4, 3 and 1 June for MG VII and VIII in 2007, 2008 and 2009, respectively. Plot size was $3.8 \mathrm{~m}$ by $6.1 \mathrm{~m}$ and consisted of four rows and $96 \mathrm{~cm}$ row spacing. Soil fertility weed control managements followed standard management recommendations for South Carolina.

Plant stand was recorded 2 wks after soybean planting (Table 2 ). Weed density was visually estimated on a scale from 0 -no weed cover to $100 \%$-full weed cover at 30 and $60 \mathrm{DAP}$ prior to glyphosate application. The most prevalent weeds observed in the research plots were palmer amaranth (Amaranthus palmeri) and yellow nutsedge (Cyperus esculentus L.). Leaf area index (LAI) and normalized difference vegetation index (NDVI) were measured on the $3.0 \mathrm{~m}$ long two center rows using LAI-2000 (Li-Cor, Lincoln, NE) and GreenSeeker $^{\mathrm{TM}}$ (NTech Industries, Inc. Ukiah, CA) at 60 and 90 DAP, respectively.
Analysis Of Variance (ANOVA) was separated for each MG using PROC MIXED procedure in SAS (SAS V. 9.2, SAS Institute, Cary, NC). Seeding rate and year were treated as fixed effects and replicate as a random effect. Treatment effects were considered significant at $\mathrm{p} \leq 0.05$. The PDIFF option in the LSMEANS statement of PROC MIXED procedure was used to compare seeding rate effect for each MG soybeans. PROC NLIN procedure in SAS evaluated relationships between weed density and seeding rates. Correlations between weed density and plant LAI/NDVI at $60 \mathrm{DAP}$ were analyzed using PROC CORR procedure in SAS.

\section{RESULTS}

Except for MG IV, the seeding rate by year interactions were significant for weed density at 30 and 60 DAP for MG V-VIII soybeans (Table 3). In general, weed density was greater at lower seeding rates for most MG soybeans at 30 and 60 DAP each year, with the exception of MG IV and VIII at 30 DAP in 2007 and MG VI at 30 DAP in 2008.

Figure 1 presents the effect of seeding rate on weed density (\% coverage) at 30 and 60 DAP for each MG by year. The variations of weed coverage with seeding rate at $30 \mathrm{DAP}$ and $60 \mathrm{DAP}$ followed a similar trend for each MG: decreasing with seeding rate by linear functions. For the same MG, the intercept and the magnitude of weed density reduction with seeding rate varied with years. However, the decline of weed density with seeding rate was similar at 30 DAP compared to 60 DAP in the same year for almost all MGs except MG IV in 2009 and MG VIII in 2007. 


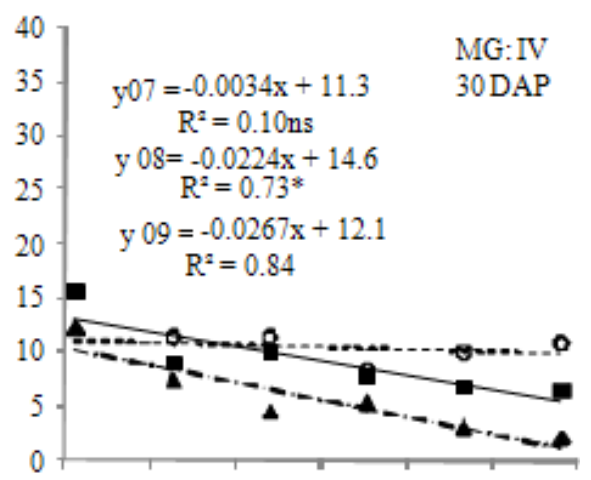

(a)

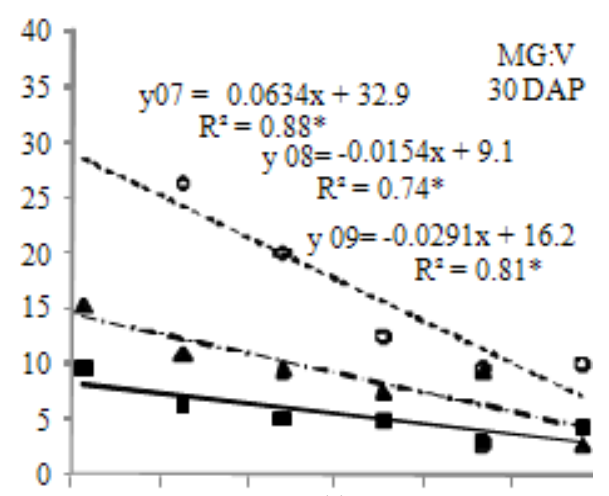

(c)

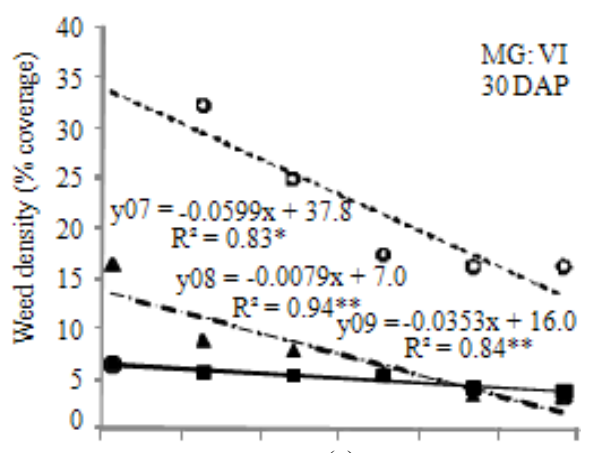

(e)

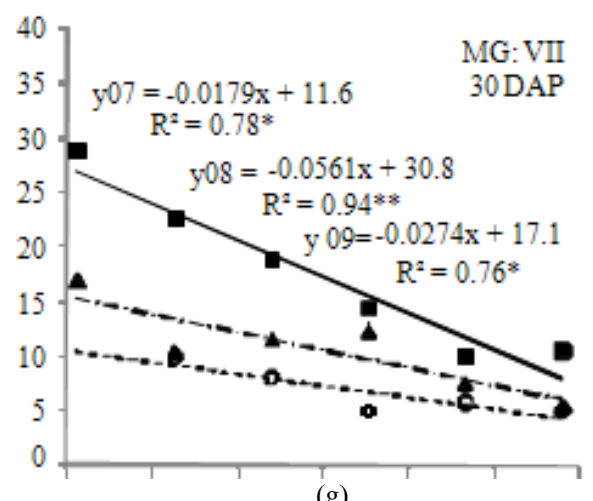

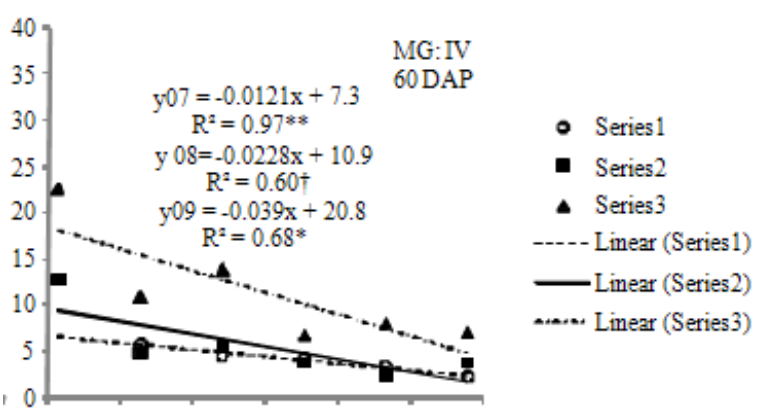

(b)

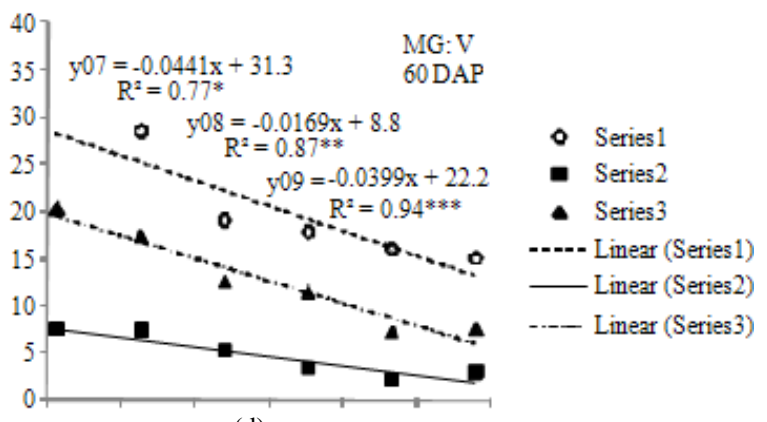

(d)

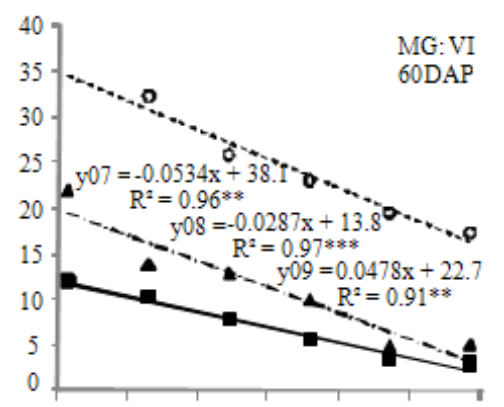

(f)

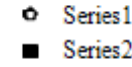

- Series 3

..... Linear (Series 1)

- Linear (Series2)

-.u-Linear (Series3)

(g)

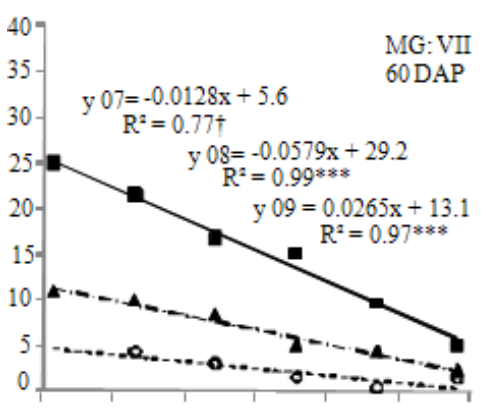

(h)
- Series 1

- Series 2

- Series 3

..... Linear (Series 1)

- Linear (Series2) -.u. Linear (Series3) 


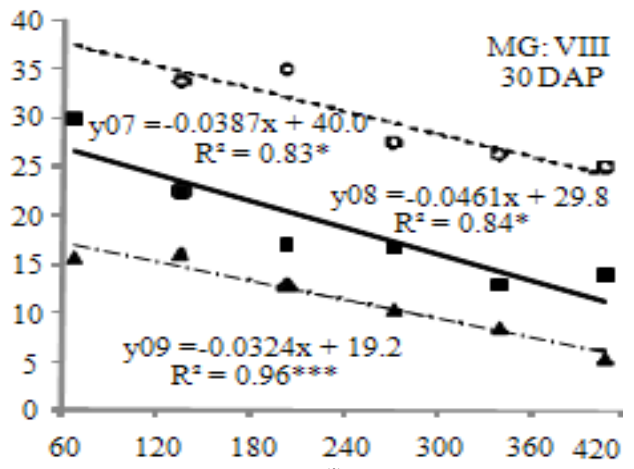

(i)

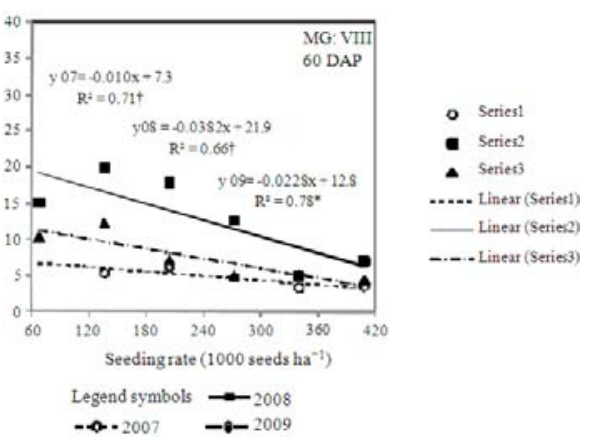

(j)

Fig. 1: Relationships between weed density (\% coverage) and seeding rate for Maturity Group (MG) IV-VIII at 30 and 60 Days After Planting (DAP) in 2007, 2008 and 2009. Each data point represents the mean of four replicates and was regressed against seeding rate, where $\mathrm{x}$ is seeding rate (seeds ha $\mathrm{h}^{-1}$ ) and $\mathrm{y}$ is percent of weed coverage, $\dagger, *, * *, * * *$ : significant at $\mathrm{p} \leq 0.10,0.05,0.01$ and 0.001 , respectively, NS: Not Significant at $\mathrm{p} \leq 0.10$

Table 3: Significance of F values from analysis of variance of weed density for Maturity Group (MG) IV-VIII from 2007-2009

\begin{tabular}{|c|c|c|c|}
\hline \multirow[b]{2}{*}{ Maturity group } & \multirow[b]{2}{*}{ Source of variation } & \multicolumn{2}{|c|}{ Weed density } \\
\hline & & 30 DAP & 60 DAP \\
\hline \multirow[t]{3}{*}{ IV } & Year & *** & $* * *$ \\
\hline & Seeding rate $(\mathrm{SR})$ & $* * *$ & $* * *$ \\
\hline & Year*SR & $\mathrm{NS}^{\dagger}$ & NS \\
\hline \multirow[t]{3}{*}{ V } & Year & $* * *$ & $* * *$ \\
\hline & SR & NS & $* * *$ \\
\hline & Year*SR & NS & $*$ \\
\hline \multirow[t]{3}{*}{ VI } & Year & $* * *$ & $* * *$ \\
\hline & SR & $* * *$ & $* * *$ \\
\hline & Year*SR & * & NS \\
\hline \multirow[t]{3}{*}{ VII } & Year & $* * *$ & $* * *$ \\
\hline & SR & $* * *$ & $* * *$ \\
\hline & Year*SR & $* * *$ & $* * *$ \\
\hline \multirow[t]{3}{*}{ VIII } & Year & $* * *$ & $* * *$ \\
\hline & SR & $* * *$ & $* * *$ \\
\hline & Year*SR & NS & $* *$ \\
\hline
\end{tabular}

Table 4: Pearson correlation coefficients between weed density and Leaf Area Index (LAI) and Normalized Difference Vegetation Index (NDVI) at 60 Days After Planting (DAP), for Maturity Group (MG) IV-VIII from 2007-2009

\begin{tabular}{|c|c|c|c|c|c|}
\hline \multirow[b]{2}{*}{ Maturity group } & \multicolumn{3}{|l|}{ LAI } & \multicolumn{2}{|l|}{$\mathrm{NDVI}^{\ddagger}$} \\
\hline & 2007 & 2008 & 2009 & 2008 & 2009 \\
\hline IV & $-0.30^{\dagger}$ & $-0.54^{* *}$ & $-0.78^{* * *}$ & $-0.56^{* *}$ & $-0.73^{* * *}$ \\
\hline V & $-0.45^{*}$ & $-0.48^{*}$ & $-0.57^{*}$ & $-0.45^{*}$ & $-0.67^{* *}$ \\
\hline VI & $-0.39^{\dagger}$ & $-0.41^{*}$ & $-0.60^{* *}$ & $-0.63^{* * *}$ & $-0.78^{* * *}$ \\
\hline VII & $-0.61^{* *}$ & $-0.57^{* *}$ & $-0.28^{\dagger}$ & $-0.70^{* * *}$ & $-0.16^{\dagger}$ \\
\hline VIII & $-0.02^{\dagger}$ & $-0.62^{* *}$ & $-0.30^{\dagger}$ & $-0.71^{* * *}$ & $-0.26^{\dagger}$ \\
\hline
\end{tabular}

***, **, *: Indicate significance at $\mathrm{p} \leq 0.001,0.01$ and 0.05 , respectively; $\dagger$ NS: Not Significant at $\mathrm{p} \leq 0.05 ; \ddagger$ : NDVI data were collected in 2008 and 2009 only

Table 4 presents Pearson correlation coefficients between weed density and LAI/NDVI at 60 DAP. Negative correlations were observed between weed density and LAI/NDVI for all MGs in 2008 and MG IV, $\mathrm{V}$ and VI in 2009. There was also a negative correlation between weed density and LAI for MG V and VII in 2007.

\section{DISCUSSION}

Decreasing weed pressure with greater seeding rates was similar to observations in organic management of soybeans (Place et al., 2009). Arce et al. (2009) also reported that weed biomass at soybean harvest was inversely related to soybean population. 
Soybean canopy usually develops more rapidly at higher seeding rate, which results in lower weed density (Harder et al. (2007).

Negative correlations between weed density and plant LAI/NDVI was expected, because weeds competed with soybeans for resources such water, nutrients and sunlight. Higher weed density would capture more resources and reduce the availability of resources for soybeans, which potentially reduces soybean growth. Though no direct report is available in literature on relationships between weed density and LAI/NDVI, greater soybean LAI and lower weed density at higher seeding rates were previously reported (Rich and Renner, 2007). Legere and Schreiber (1989) also indicated that soybean produced higher LAI accumulation rate over time from weed free stands compared to soybeans in weedy stands.

\section{CONCLUSION}

Weed density at 30 and 60 DAP was inversely related to seeding rate for most $\mathrm{MG}$ soybeans except MG IV at 30 DAP in 2007. Weed density was generally lower at higher seeding rates for all MG soybeans at 30 and 60 DAP, except MG IV and VIII at 30 DAP in 2007 and MG VI at 30 DAP in 2008. However, weed density reduction with increasing seeding rate varied over years due to mostly different precipitation each growing season. Negative correlations were also observed between weed density and plant LAI/NDVI for all MGs in 2008 and MG IV through VI in 2009. This study indicates that the effect of increasing seeding rate on weed pressure may vary over years and MG soybeans.

\section{ACKNOWLEDGMENT}

The authors thank the South Carolina Soybean Board for grant support. This material is also based on work supported by NIFA/USDA, under project number SC-1700328. Technical Contribution no. is 5809 of the Clemson University Experiment Station.

\section{REFERENCES}

Arce, G.D., P. Pedersen and R.G. Hartzler, 2009. Soybean seeding rate effects on weed management. Weed Technol., 23: 17-22. DOI: 10.1614/WT-08-060.1

Buhler, D.D., 1999. Weed population responses to weed control practices. II. Residual effects on weed populations, control, and glycine max yield. Weed Sci., 47: 423-426.

Harder, D.B., C.L. Sprague and K.A. Renner, 2007. Effect of soybean row width and population on weeds, crop yield, and economic return. Weed Technol., 21: 744-752. DOI: 10.1614/WT-06-122.1

Legere, A. and M.M. Schreiber, 1989. Competition and canopy architecture as affected by soybean (glycine max) row width and density of redroot pigweed (amaranthus retroflexus). Weed Sci., 37: 84-92.

Place, G.T., S.C. Reberg-Horton, J.E. Dunphy and A.N. Smith, 2009. Seeding rate effects on weed control and yield for organic soybean production. Weed Technol., 23: 497-502. DOI: 10.1614/WT-08-134.1

Rich, A.M. and K.A. Renner, 2007. Row spacing and seeding rate effects on eastern black nightshade (solanum ptycanthum) and soybean. Weed Technol., 21: 124-130. DOI: 10.1614/WT-04-220.1

Swanton, C.J. and S.F. Weise, 1991. Integrated weed management: The rationale and approach. Weed Technol., 5: 657-663.

Yelverton, F.H. and H.D. Coble, 1991. Narrow row spacing and canopy formation reduces weed resurgence in soybeans (Glycine max). Weed Technol., 5: 169-174. 